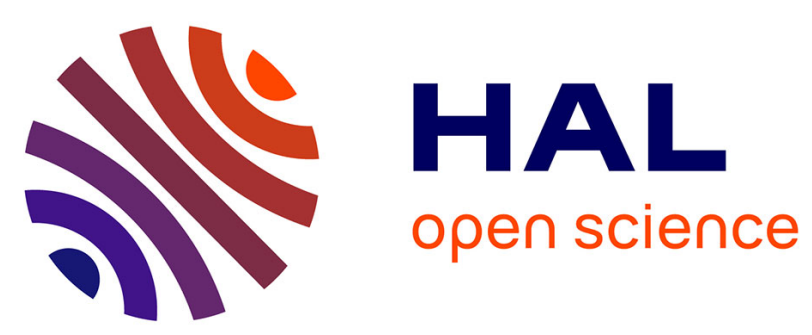

\title{
A Novel PITX2c Gain-Of-Function Mutation, p.Met207Val, in Patients With Familial Atrial Fibrillation
}

Asma Mechakra, Tim Footz, Michael Walter, Amelia Aránega, Francisco

Hernández-Torres, Elodie Morel, Gilles Millat, Yi-Qing Yang, Mohamed

Chahine, Philippe Chevalier, et al.

\section{To cite this version:}

Asma Mechakra, Tim Footz, Michael Walter, Amelia Aránega, Francisco Hernández-Torres, et al.. A Novel PITX2c Gain-Of-Function Mutation, p.Met207Val, in Patients With Familial Atrial Fibrillation. American Journal of Cardiology, 2019, 123 (5), pp.787-793. 10.1016/j.amjcard.2018.11.047 . inserm02897422

\section{HAL Id: inserm-02897422 https://www.hal.inserm.fr/inserm-02897422}

Submitted on 12 Jul 2020

HAL is a multi-disciplinary open access archive for the deposit and dissemination of scientific research documents, whether they are published or not. The documents may come from teaching and research institutions in France or abroad, or from public or private research centers.
L'archive ouverte pluridisciplinaire $\mathbf{H A L}$, est destinée au dépôt et à la diffusion de documents scientifiques de niveau recherche, publiés ou non, émanant des établissements d'enseignement et de recherche français ou étrangers, des laboratoires publics ou privés. 


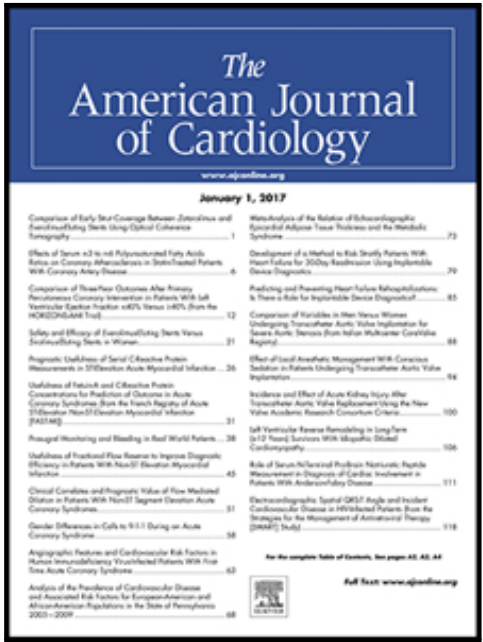

A Novel PITX2c Gain-Of-Function Mutation, p.Met207Val, in Patients With Familial Atrial Fibrillation

Asma Mechakra PhD, Tim Footz MSc, Michael Walter PhD, Amelia Aránega $\mathrm{PhD}$, Francisco Hernández-Torres PhD, Elodie Morel PhD, Gilles Millat PhD , Yi-Qing Yang MD, PhD , Mohamed Chahine PhD , Philippe Chevalier MD, PhD , Georges Christé PhD

PII: S0002-9149(18)32152-0

DOI: https://doi.org/10.1016/j.amjcard.2018.11.047

Reference: AJC 23659

To appear in:

The American Journal of Cardiology

Received date:

20 April 2018

Revised date: 16 November 2018

Please cite this article as: Asma Mechakra PhD, Tim Footz MSc, Michael Walter PhD, Amelia Aránega PhD , Francisco Hernández-Torres PhD, Elodie Morel PhD, Gilles Millat PhD , Yi-Qing Yang MD, PhD , Mohamed Chahine PhD, $\quad$ Philippe Chevalier MD, PhD , Georges Christé PhD , A Novel PITX2c Gain-Of-Function Mutation, p.Met207Val, in Patients With Familial Atrial Fibrillation, The American Journal of Cardiology (2018), doi: https://doi.org/10.1016/j.amjcard.2018.11.047

This is a PDF file of an unedited manuscript that has been accepted for publication. As a service to our customers we are providing this early version of the manuscript. The manuscript will undergo copyediting, typesetting, and review of the resulting proof before it is published in its final form. Please note that during the production process errors may be discovered which could affect the content, and all legal disclaimers that apply to the journal pertain. 


\section{A Novel PITX2c Gain-Of-Function Mutation, p.Met207Val, in}

\section{Patients With Familial Atrial Fibrillation}

Asma Mechakra, $\mathrm{PhD}^{\mathrm{a}}$, Tim Footz, MSc ${ }^{\mathrm{b}}$, Michael Walter, $\mathrm{PhD}^{\mathrm{b}}$, Amelia Aránega, $\mathrm{PhD}^{\mathrm{c}}$, Francisco Hernández-Torres, $\mathrm{PhD}^{\mathrm{c}}$, Elodie Morel, $\mathrm{PhD}^{\mathrm{a}}$, Gilles Millat, $\mathrm{PhD}$, Yi-Qing Yang, MD, $\mathrm{PhD}^{\mathrm{d}}$, Mohamed Chahine, $\mathrm{PhD}^{\mathrm{e}}$, Philippe Chevalier, $\mathrm{MD}, \mathrm{PhD}^{\mathrm{a}}$, Georges Christé, $\mathrm{PhD}^{\mathrm{a}}$

${ }^{a}$ EA4612 Neurocardiologie, Université Lyon 1, 69373 Lyon, France. ${ }^{b}$ Department of Medical Genetics, University of Alberta, Edmonton, Alberta, T6G 2H7 Canada. ${ }^{\circ}$ Department of Experimental Biology, Faculty of Experimental Sciences, University of Jaén, 23071 Jaén, Spain. ${ }^{\mathrm{d}}$ Department of Cardiology, Laboratory of Cardiovascular Research and Central Laboratory, Shanghai Chest Hospital, Shanghai Jiao Tơng University, Shanghai, China. ${ }^{\mathrm{e}}$ Institut Universitaire en Santé Mentale, Québec City, QC G1J 2G3, Canada.

\section{Corresponding author:}

Georges Christé, $\mathrm{PhD}$

Université Lyon 1, EA4612 Neurocardiology

8 Avenue Rockefeller

69373 Lyon Cedex 08, France.

Tel: +33627556373

Fax: +33478777185

Email: christe.georges@ laposte.net

Running head: PITX2c gain-of-function mutation in AF 


\section{Abstract}

Genome-wide studies have associated several genetic variants upstream of PITX2 on chromosome 4q25 with atrial fibrillation (AF), suggesting a potential role of PITX2 in AF. Our study aimed at identifying rare coding variants in PITX2 predisposing to AF. The Polymerase chain reaction (PCR) sequencing of PITX2c was performed in 60 unrelated patients with idiopathic AF. The p.Met207Val variant was identified in 1 out of 60 French individuals with early onset AF and in none of 389 French referents. This variant, located in the inhibitory domain 1 distal to the homeodomain, was evaluated by the software MutationTaster as a disease-causing mutation with a prøbability of 0.999 . Reporter gene assays demonstrated that p.Met207Val caused a 3.1-fold increase in transactivational activity of PITX2c in HeLa cells in comparison with its wild-type (WT) counterpart. When the variant was co-expressed with WT PITX2c in the HL-1 immortalized mouse atrial cell line, this gain-of-function caused an increase in the mRNA level of KCNH2 (2.6-fold), SCN1B (1.9-fold), GJA5 (3.1-fold), GJA1 (2.1-fold) and KCNQ1 in the homozygous form (1.8-fold). These genes encode for the $\mathrm{IKr}$ channel $\alpha$ subunit, the $\beta-1 \mathrm{Na}^{+}$channel subunit, connexin 40 , and connexin 43 and the IKs channel $\alpha$ subunit, respectively. These conditions may contribute the p.Met207Val variant to the propensity to AF found in patients carrying these varrants. In conclusion, the present report is the first to associate a gain-of-function mutation of PITX2c with increased vulnerability to AF, therefore, restoration of normal PITX2c function may be a potential therapeutic target in AF patients.

Keywords : PITX2, transcription factor, atrial fibrillation, variant, gain-of-function 


\section{Introduction}

The physiopathology of AF is poorly understood and the therapeutic measures available are not sufficient. The SNP most significantly associated with AF is located in a non-coding region of chromosome $4 q 25$, approximately 150,000 base pairs upstream of the gene coding for the paired-like homeodomain transcription factor 2 (PITX2, MIM 180500). ${ }^{1}$ PITX2c is the major protein isoform expressed in the hearts of mice ${ }^{2}$ and humans $s^{3,4}$ and is involved in generating and maintaining morphological and electrical cardiac asymmetry. PITX2c deficiency causes changes in atrial electrical properties that favor $\mathrm{AF}^{3,6-8}$ These observations suggest a link between the PITX2c isoform and AF. Our objective was therefore to search for genetic variants in PITX2 in our cohort of patients with AF.

\section{Methods}

A brief description of the methods follows, a complete account of methods is provided in the Supplemental Material available online. The experimental protocols were approved by the local institutional ethics committee on human subject research of the Louis Pradel Hospital (Protocol reference number: CAL 2012-030). A sample of 60 unrelated patients with idiopathic AF was recruited at the Cardiologic Hospital of Lyon. Other recognized cardiovascular diseases, hypertension and metabolic or pulmonary diseases had been excluded. Genomic DNA from all participants was extracted from whole blood samples. The entire coding sequence of PITX2 was sequenced using Sanger sequencing. Sequencing of genes previously associated with AF was also performed: $K C N Q 1, K C N H 2, K C N A 5, S C N 5 A$, GJA1, GJA5 and GJC1. To evaluate the transactivation activity of PITX2c proteins, Henrietta 
Lacks' cervical tumor cells (HeLa) were co-transfected with a PITX2c plasmid and a SLC13A3 luciferase reporter plasmid including PITX2 binding site A. ${ }^{9}$ The transactivation activity of wild-type (WT) and variant PITX2c was evaluated by luminometry. We evaluated the ability of WT and mutated PITX2c proteins to interact with the DNA bicoid binding site by an electrophoretic mobility shift assay. Non-denaturating polyacrylamide gel electrophoresis was performed on a mixture of double-stranded Cy3-labelled DNA (at 0.5 $\mu \mathrm{M})$ and $40 \mu \mathrm{g}$ of whole-cell extracts of HeLa cells transfected with a PITX2c plasmid. The amount of PITX2c protein expressed by the cells was monitored by a western blot assay. The effect of the variant on mRNA transcription of ion channel genes was measured 24 hours after transfection with WT or variant PITX2c plasmids of immortalized mouse atrial cells (HL-1, obtained from Dr. Claycomb). ${ }^{10}$ Total RNA $(0.5 \mu \mathrm{g})$ was used to prepare cDNA and quantitative real-time polymerase chain reaction (RT-PCR) measurement was performed using appropriate primers. Quantitative analyses of Western blot and mRNA data were performed using Prism 6 software (GraphPad, California, USA). Statistical analyses of quantitative experimental data were performed using the unpaired Student t-test. A two-sided p-value $<0.05$ was considered statistically significant. The following web resources have been used: Exome Variant Server (EVS), NHLBI GO Exome Sequencing Project (ESP), Seattle, WA (URL: http://evs,gs.washington.edu/EVS/) [October 2018 accessed]. Exome Aggregation Consortium (ExAC), Cambridge, MA (URL: http://exac.broadinstitute.org) [October 2018 accessed]. Online Mendelian Inheritance in Man (OMIM), (URL: http://www.omim.org/) [October 2018 accessed]. Single Nucleotide Polymorphism database, the National Center for Biotechnical Information (http://www.ncbi.nlm.nih.gov/SNP/). The OMIM accession number for the PITX2 sequence reported in this work is MIM 180500. 


\section{Results}

The clinical characteristics of the study samples are provided in Table 1. Mutation screening of PITX2 resulted in the identification of a non-synonymous variant c.619A $>\mathrm{G}$ (p.Met207Val, rs138163892) (Figure 1A). The amino acid position of the variant is depicted in Figure 1B. The alignment of a segment of the amino acid sequences of PITX2c across several species (Supplemental Table S4) shows that the methionine residue at position 207 is highly conserved. The p.Met207Val variant was found in a patient and in none of the 389 unrelated referents. In addition, we investigated p.Met207Val co-segregation with atrial fibrillation in our pedigree and found that p.Met207Val co-segregated with the AF phenotype (Figure 1C). According to the EVS database, p.Met207Val was found in 3 individuals of a general population of 8597 European Americans and in no individual of a general population of 4406 African Americans. Of note, atrial fibrillation is not an exclusion criterion of these cohorts. ExAC reports 37 heterozygous carriers out of a total European population of 121304 individuals (allele frequency $3.05^{*} 10^{-4}$ ). A search within the Single Nucleotide Polymorphism database or within 1000 Genomes yielded no occurrence of the p.Met207Val variant. No variant was detected in KCNQ1, KCNH2, KCNA5, SCN5A, GJA1, GJA5 and GJC1 in our propositus. Few variants were found in $\mathrm{KCNH} 2$, GJA1, and GJA5 in other patients of our AF sample. sample of AF patients. Using gene reporter assays, WT-PITX2c showed a level of activation about 13-fold higher than the empty expression vector (Figure 2A). The mutated PITX2c showed significantly increased activation of the reporter in comparison with WT PITX2c ( 3.1-fold). However, the transfection with the variant construct in HeLa cells resulted in the production of $\sim$ 1.7-fold more PITX2c protein than with the WT construct (Figure 2B). Taking this effect into account, we estimated that the normalized activity of the variant 
protein was $\sim 1.8$-fold higher than that of the WT. The transactivation effects did not result from a change in intracellular trafficking of the variant protein (Figure 2C). In the electrophoretic mobility shift assay shown in Figure 3, WT and mutated PITX2c proteins were shifted similarly in the presence of a DNA oligomer probe containing the canonical PITX2 binding element TAATCC (upper panel). The intensities of these bands were parallel to those in Western blots of PITX2c proteins (lower panel), indicating a similar affinity to the DNA probe. In the HL-1 cardiac atrial cell line, we assessed the transcriptional effect of the variant on several genes that encode key proteins involved in AF (GJA5, GJA1, SCN1B, $K C N Q 1, K C N H 2$ and $S C N 5 A$ ) using qRT-PCR (Figure 4). This was done under 3 conditions: in cells transfected with either a WT plasmid or the variant PITX2c plasmid (200 ng/well) or with both plasmids in combination (100 ng/well of each), to imitate the heterozygous situation. The mRNA levels with the p.Met207Valalone or in combination with the WT were normalized to those obtained with the WT alone. There were no significant differences in the amount of PITX2c expressed in HL-1 cells under these 3 conditions, using quantitative Western blot (Figure 4 A and B). As a negative control, non-transfected cells did not yield detectable amounts of PITX2c and the mRNA levels of the target genes explored were not changed by the empty vector (Figure 5). The relative changes in mRNA levels caused by the variant are depicted in Figure $\mathbf{4} \mathbf{C}$ to $\mathbf{H}$ and recapitulated in Table 2. These effects indicate that p.Met207Val had a larger potency than the WT in activating the transcription of connexin and jon channel genes tested, as seen with the reporter gene assays in HeLa cells (Figure 2). Further, apart from $K C N Q 1$, similar changes were observed when the variant was cotransfected with the WT, which corresponds to its heterozygous presentation in the carriers. 


\section{Discussion.}

In the present study, we report a variant in PITX2, p.Met207Val, in association with familial atrial fibrillation. In HeLa cells, the variant p.Met207Val induced a gain of function as revealed by the increase in the transactivation activity of PITX2c (Figure 2). In the HL-1 cardiac cell line, p.Met207Val resulted in increased mRNA levels of $K C N H 2$ when coexpressed with WT PITX2c (Figure 4). Mutations in $\mathrm{KCNH} 2$ associated with familial AF have been shown to cause gain-of-function effects on the $\mathrm{I}_{\mathrm{Kr}}$ current. ${ }^{11,12}$ Such a gain-offunction may trigger AF through shortening of the atrial action potential duration (APD) and, hence, favour re-entry mechanisms. The variant p.Met207Val also increased the level of SCN1B mRNA 1 compared to WT, whereas SCN5A mRNA levels were not significantly affected. An increase in the expression of the $\mathrm{Na}_{\mathrm{v}} \beta 1$ regulatory subunit may nevertheless cause an increase in the amount of fast $\mathrm{Na}^{+}$current by facilitating surface expression of the $\mathrm{Na}_{\mathrm{v}} 1.5 \alpha$-subunit together with its $\beta 1$ regulatory subunit. ${ }^{13}$ Such a gain-of-function effect was found associated with $\mathrm{AF}{ }^{14}$ Additionally, overexpression of $S C N 1 B$ in nerve cells increased the density of $\mathrm{K}_{\mathrm{v}} 4.2$ channels $^{15}$ and SCN1Bb, a splice variant of the SCN1B gene, when coexpressed with $\mathrm{K}_{\mathrm{v}} 4.3$ in TsA201 cells, increased the outward current. ${ }^{16}$ In the human atrium, the transient outward current $I_{t o}$ is carried by heterotetramers of $K_{v} 4.2$ and $K_{v} 4.3$ subunits, ${ }^{17}$ and increasing their expression might contribute to shortening the APD. ${ }^{17}$ The variant p.Met207Val increased GJA5 and GJA1 mRNA levels. In human atrial tissue from AF patients, increased levels of $\mathrm{Cx} 40$ and $\mathrm{Cx} 43^{18}$ have been found and a rise in internal resistivity was correlated with the ratio $\mathrm{Cx} 40 /(\mathrm{Cx} 40+\mathrm{Cx} 43) .{ }^{19}$ Changes in the expression of $\mathrm{Cx} 40$ have been shown to either increase or decrease atrial conduction velocity, ${ }^{20}$ which may actually cause AF either way according to a recent study associating both shortened and prolonged 
PR-intervals to $\mathrm{AF}^{21}$ Our data are supported by the findings of Y. Huang and co-workers ${ }^{22}$ showing > 800 differentially expressed genes, including increased transduction of KCNH2 (9fold) and KCNQ1 (3.3-fold), when PITX2c was over-expressed in HEK293 cells. Analysis of their data using gene ontology database biological processes shows 2 GO terms related to cardiac function among the most enriched terms ("regulation of heart rate by cardiac conduction" and "cardiac muscle cell action potential involved in contraction"). Moreover, in another study, PITX2 CHIPseq analysis revealed peaks near several genes related to FA (KCNQ1, Cav1, and Zfhx3) suggesting a direct regulation by PITX2. ${ }^{23}$ Our reporter gene assays showed a gain-of-function of p.Met207Val in comparison to the wild type construct (Figure 2). A number of previous studies have shown a link between AF and decreased expression or activity of PITX2c in the left atrium in humans and transgenic mice, ${ }^{7,8}$ or with loss-of-function PITX2 mutations. ${ }^{24,25}$ However, PITX2 expression has been found to be increased in the left atrium ${ }^{26}$ and in right atrial myocytes ${ }^{27}$ from AF patients. Thus both PITX2 gain and loss of function are associated with AF. Besides, among $>50$ mutations of PITX2 related to the Axenfeld-Rieger syndrome most are loss-of-function mutations, but 6 of them are gain-of-function mutations. ${ }^{28-30}$ In conclusion, we identified a rare variant (p.Met207Val) in PITX2 that was associated with familial AF. The variant increased transcriptional activity of PITX2c and increased the transcription of GJA1, GJA5, KCNH2, and $S C N 1 B$ in an atrial cardiac cell line. As for several other genes, gain-of-function as well as loss-of-function of PITX2c might favor AF, pointing out to the rupture of the balance of PITX2c activity as a unifying concept. Thus, restoration of a balanced PITX2c activity might be a new goal for AF prevention and therapy. 
Our study is limited by the low frequency of p.Met207Val in publicly available databases (minor allele frequency $=0.03 \%$ in European samples in ExAC, See Web Resources, and in the Exome Variant Server, See Web Resources), in combination with the limited size of our case sample, warrants replication in a larger study of individuals with early onset AF, to confirm the association observed for p.Met207Val. Our discussion of the possible proarrhythmic consequences is made under the assumption that the transcriptional changes would cause corresponding changes in the functional activity of the proteins, which we did not investigate. Further studies should also address the direct and indirect pathways from mutated PITX2c through mRNAs transcription down to expression of endpoint proteins.

No disclosures.

Acknowledgment The authors are greatly indebted to the study participants for their devotion to the study. This work was supported by the Université Claude Bernard Lyon 1, by charity funds of the ALMS (Association Lyonnaise Contre la Mort Subite) and by the grants from the National Natural Science Fund of China (81270161, 81370301 and 81470372), the Natural Science Fund of Shanghai, China (15ZR1438100), and the Key Program of Basic Research of Shanghai, China (14JC1405500).

\section{References}

1. Gudbjartsson DF, Arnar DO, Helgadottir A, Gretarsdottir S, Holm H, Sigurdsson A, Jonasdottir A, Baker A, Thorleifsson G, Kristjansson K, Palsson A, Blondal T, Sulem P, Backman VM, Hardarson GA, Palsdottir E, Helgason A, Sigurjonsdottir R, Sverrisson JT, Kostulas K, Ng MC, Baum L, So WY, Wong KS, Chan JC, Furie KL, Greenberg SM, Sale 
M, Kelly P, MacRae CA, Smith EE, Rosand J, Hillert J, Ma RC, Ellinor PT, Thorgeirsson G, Gulcher JR, Kong A, Thorsteinsdottir U, Stefansson K. Variants conferring risk of atrial fibrillation on chromosome 4q25. Nature 2007;448:353-357.

2. Franco D, Chinchilla A, Aranega AE. Transgenic insights linking pitx2 and atrial arrhythmias. Front Physiol 2012;3:206.

3. Wang J, Klysik E, Sood S, Johnson RL, Wehrens XH, Martin JF. Pitx2 prevents susceptibility to atrial arrhythmias by inhibiting left-sided pacemaker specification. Proc Natl Acad Sci U S A 2010;107:9753-9758.

4. Kahr PC, Piccini I, Fabritz L, Greber B, Scholer H, Scheld HH, Hoffmeier A, Brown NA, Kirchhof P. Systematic analysis of gene expression differences between left and right atria in different mouse strains and in human atrial tissue. PLOS ONE 2011;6:e26389.

5. Ai D, Liu W, Ma L, Dong F, Lu MF, Wang D, Verzi MP, Cai C, Gage PJ, Evans S, Black BL, Brown NA, Martin JF. Pitx2 regulates cardiac left-right asymmetry by patterning second cardiac lineage-derived myocardium. Dev Biol 2006;296:437-449.

6. Mommersteeg MT, Brown NA, Prall OW, Gier-de Vries C, Harvey RP, Moorman AF, Christoffels VM. Pitx2c and Nkx2-5 are required for the formation and identity of the pulmonary myocardium. Circ Res 2007;101:902-909.

7. Kirchhof P, Kahr PC, Kaese S, Piccini I, Vokshi I, Scheld HH, Rotering H, Fortmueller L, Laakmann S, Verheule S, Schotten U, Fabritz L, Brown NA. PITX2c is expressed in the adult 
left atrium, and reducing Pitx2c expression promotes atrial fibrillation inducibility and complex changes in gene expression. Circ Cardiovasc Genet 2011;4:123-133.

8. Chinchilla A, Daimi H, Lozano-Velasco E, Dominguez JN, Caballero R, Delpon E, Tamargo J, Cinca J, Hove-Madsen L, Aranega AE, Franco D. PITX2 insufficiency leads to atrial electrical and structural remodeling linked to arrhythmogenesis. Circ Cardiovasc Genet 2011;4:269-279.

9. Strungaru MH, Footz T, Liu Y, Berry FB, Belleau P, Semina EV, Raymond V, Walter MA. PITX2 is involved in stress response in cultured human trabecular meshwork cells through regulation of SLC13A3. Invest Ophthalmol Vis Sci 2011;52:7625-7633.

10. Claycomb WC, Lanson NA, Jr., Stallworth BS, Egeland DB, Delcarpio JB, Bahinski A, Izzo NJ, Jr. HL-1 cells: a cardiac muscle cell line that contracts and retains phenotypic characteristics of the adult cardiomyocyte. Proc Natl Acad Sci U S A 1998;95:2979-2984.

11. Ghouse J, Have CT, Weeke P, Bille NJ, Ahlberg G, Balslev-Harder M, Appel EV, Skaaby T, Olesen SP, Grarup N, Linneberg A, Pedersen O, Haunso S, Hastrup SJ, Hansen T, Kanters JK, Salling OM. Rare genetic variants previously associated with congenital forms of long QT syndrome have little or no effect on the QT interval. Eur Heart J 2015;36:2523-2529.

12. Hong K, Bjerregaard P, Gussak I, Brugada R. Short QT syndrome and atrial fibrillation caused by mutation in KCNH2. J Cardiovasc Electrophysiol 2005;16:394-396.

13. Xiao J, Liang D, Chen YH. The genetics of atrial fibrillation: from the bench to the bedside. Annu Rev Genomics Hum Genet 2011;12:73-96. 
14. Makiyama T, Akao M, Shizuta S, Doi T, Nishiyama K, Oka Y, Ohno S, Nishio Y, Tsuji K, Itoh H, Kimura T, Kita T, Horie M. A novel SCN5A gain-of-function mutation M1875T associated with familial atrial fibrillation. J Am Coll Cardiol 2008;52:1326-1334.

15. Marionneau C, Carrasquillo Y, Norris AJ, Townsend RR, Isom LL, Link AJ, Nerbonne JM. The sodium channel accessory subunit $\operatorname{Nav} \beta 1$ regulates neuronal excitability through modulation of repolarizing voltage-gated K(+) channels. J Neurosci 2012;32:5716-5727.

16. Hu D, Barajas-Martinez H, Medeiros-Domingo A, Crotti L, Veltmann C, Schimpf R, Urrutia J, Alday A, Casis O, Pfeiffer R, Burashnikov E, Caceres G, Tester DJ, Wolpert C, Borggrefe M, Schwartz P, Ackerman MJ, Antzelevitch C. A novel rare variant in SCN1Bb linked to Brugada syndrome and SIDS by combined modulation of $\mathrm{Na}(\mathrm{v}) 1.5$ and $\mathrm{K}(\mathrm{v}) 4.3$ channel currents. Heart Rhythm 2012;9:760-769.

17. Niwa N, Nerbonne JM. Molecular determinants of cardiac transient outward potassium current (I(to)) expression and regulation. J Mol Cell Cardiol 2010;48:12-25.

18. Wetzel U, Boldt A, Lauschke J, Weigl J, Schirdewahn P, Dorszewski A, Doll N, Hindricks G, Dhein S, Kottkamp H. Expression of connexins 40 and 43 in human left atrium in atrial fibrillation of different aetiologies. Heart 2005;91:166-170.

19. Dhillon PS, Chowdhury RA, Patel PM, Jabr R, Momin AU, Vecht J, Gray R, Shipolini A, Fry $\mathrm{CH}$, Peters NS. Relationship between connexin expression and gap-junction resistivity in human atrial myocardium. Circ Arrhythm Electrophysiol 2014;7:321-329. 
20. Chaldoupi SM, Loh P, Hauer RN, de Bakker JM, van Rijen HV. The role of connexin40 in atrial fibrillation. Cardiovasc Res 2009;84:15-23.

21. Nielsen JB, Pietersen A, Graff C, Lind B, Struijk JJ, Olesen MS, Haunso S, Gerds TA, Ellinor PT, Kober L, Svendsen JH, Holst AG. Risk of atrial fibrillation as a function of the electrocardiographic PR interval: Results from the Copenhagen ECG Study. Heart Rhythm 2013;10:1249-1256.

22. Huang Y, Huang K, Boskovic G, Dementieva Y, Denvir J, Primerano DA, Zhu GZ. Proteomic and genomic analysis of PITX2 interacting and regulating networks. FEBS Lett 2009;583:638-642.

23. Tao Y, Zhang M, Li L, Bai Y, Zhou Y, Moon AM, Kaminski HJ, Martin JF. Pitx2, an atrial fibrillation predisposition gene, directly regulates ion transport and intercalated disc genes. Circ Cardiovasc Genet 2014;7:23-32.

24. Yang YQ, Xu YJ, Li RG, Qu XK, Fang WY, Liu X. Prevalence and spectrum of PITX2c mutations associated with familial atrial fibrillation. Int J Cardiol 2013;168:2873-2876.

25. Zhou YM, Zheng PX, Yang YQ, Ge ZM, Kang WQ. A novel PITX2c loss of function mutation underlies lone atrial fibrillation. Int J Mol Med 2013;32:827-834.

26. Gore-Panter SR, Hsu J, Hanna P, Gillinov AM, Pettersson G, Newton DW, Moravec CS, Van Wagoner DR, Chung MK, Barnard J, Smith JD. Atrial Fibrillation associated chromosome 4q25 variants are not associated with PITX2c expression in human adult left atrial appendages. PLoS ONE 2014;9:e86245. 
27. Perez-Hernandez M, Matamoros M, Barana A, Amoros I, Gomez R, Nunez M, Sacristan S, Pinto A, Fernandez-Aviles F, Tamargo J, Delpon E, Caballero R. Pitx2c increases in atrial myocytes from chronic atrial fibrillation patients enhancing IKs and decreasing ICa,L. Cardiovasc Res 2016;109:431-441.

28. Tumer Z, Bach-Holm D. Axenfeld-Rieger syndrome and spectrum of PITX2 and FOXC1 mutations. Eur J Hum Genet 2009;17:1527-1539.

29. Priston M, Kozlowski K, Gill D, Letwin K, Buys Y, Levin AV, Walter MA, Heon E. Functional analyses of two newly identified PITX2 mutants reveal a novel molecular mechanism for Axenfeld-Rieger syndrome. Hum Mol Genet 2001;10:1631-1638.

30. Saadi I, Toro R, Kuburas A, Semina E, Murray JC, Russo AF. An unusual class of PITX2 mutations in Axenfeld-Rieger syndrome. Birth Defects Res A Clin Mol Teratol 2006;76:175181. 


\section{Figure Legends}

p.Met207Val

Figure 1. Detection of the PITX2c variant, p.M207v, in patients with familial AF. A. The sequence electropherogram of the patient carrying the heterozygous c.619A $>\mathrm{G}$ variant. B.

Schematic representation of PITX2c and location of the detected variant. Numbers are in aminoacid residues. p.Met207Val is located in the $\mathrm{C}$-terminal domain. $\mathrm{AD} 1$ : common sequence, HD: Homeodomain, ID1: transcriptional inhibitory domain 1, AD2: second common sequence, ID2: Transcriptional inhibitory domain 2. The 5-AA sequence important for transcriptional activity of the N-terminal of PITX2c (33-37) is LAMAS. C. Pedigree showing familial aggregation of p.Met207Val. The mother of the proband and her brother were diagnosed with AF (as did their mother) and both carried p.Met207Val. Arrow $=$ the proband (III-3); +/- = heterozygous for the mutation; Squares = male gender; Circles $=$ female gender; Black-filled symbols = documented AF; Grey-filled symbol = arrhythmia symptoms but no documented AF; Open symbols $=$ no AF; Crossed symbols, not alive at inclusion .

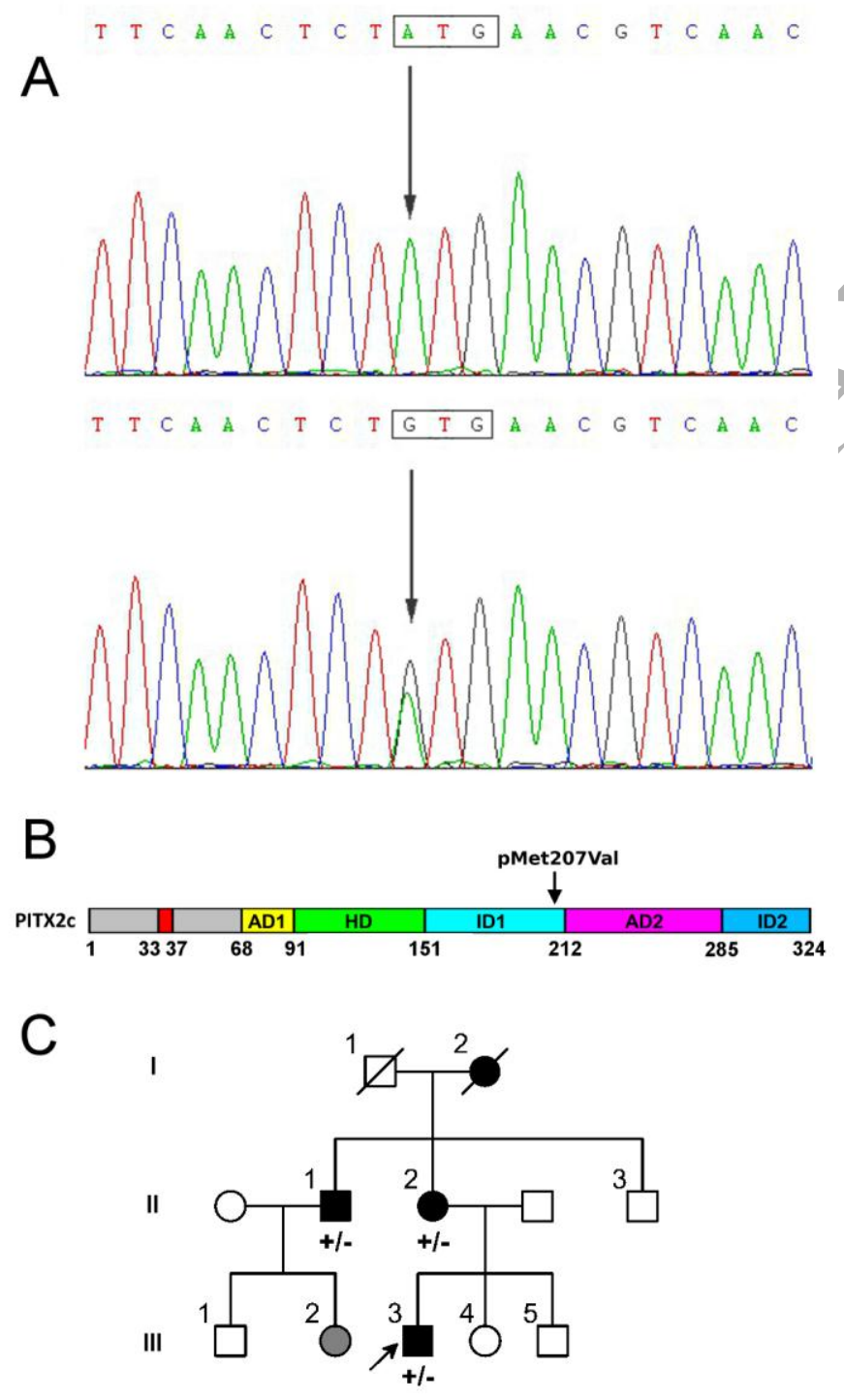


Figure 2. Reporter gene assay of PITX2c variants in HeLa cells. Efficiency of activation of the SLC13A3-reporter plasmid by PITX2c proteins in HeLa cells. A: Average values for 3 measurements in each of 3 separate transfections of each plasmid $(n=9)$ are shown. HeLa cells were transfected with either the empty vector, a vector encoding the WT PITX2c, or a vector encoding the p.Met207Val PITX2c variant. These cells were co-transfected with the SLC13A3 reporter containing the PITX2 binding site (black bars). Asterisks (**) denote that activation was significantly stronger with p.Met207Val versus WT $(\mathrm{p}<0.001)$ as calculated from comparisons with Student's t-test. B: Quantitative immunoblot of PITX2c protein expression in lysates of HeLa cells transfected with WT or p.Met207Val plasmids or with the empty vector (empty). Densities were normalized to the expression of co-transfected alphatubulin and expressed with reference to the value for WT PITX2c. C: Immunofluorescence detection of recombinant PITX2c in HeLa cells. Upper panels show the localization of Xpress-PITX2c labelling by mouse Anti-Xpress Ab (1:500) detected by goat Anti-Mouse-IgG coupled to Cyanine3 (1:500) in cells transfected with the WT cDNA (left) or the p.Met207Val variant cDNA (right). Lower panels show the same images merged with the corresponding images of nuclei labelled with DAPI.
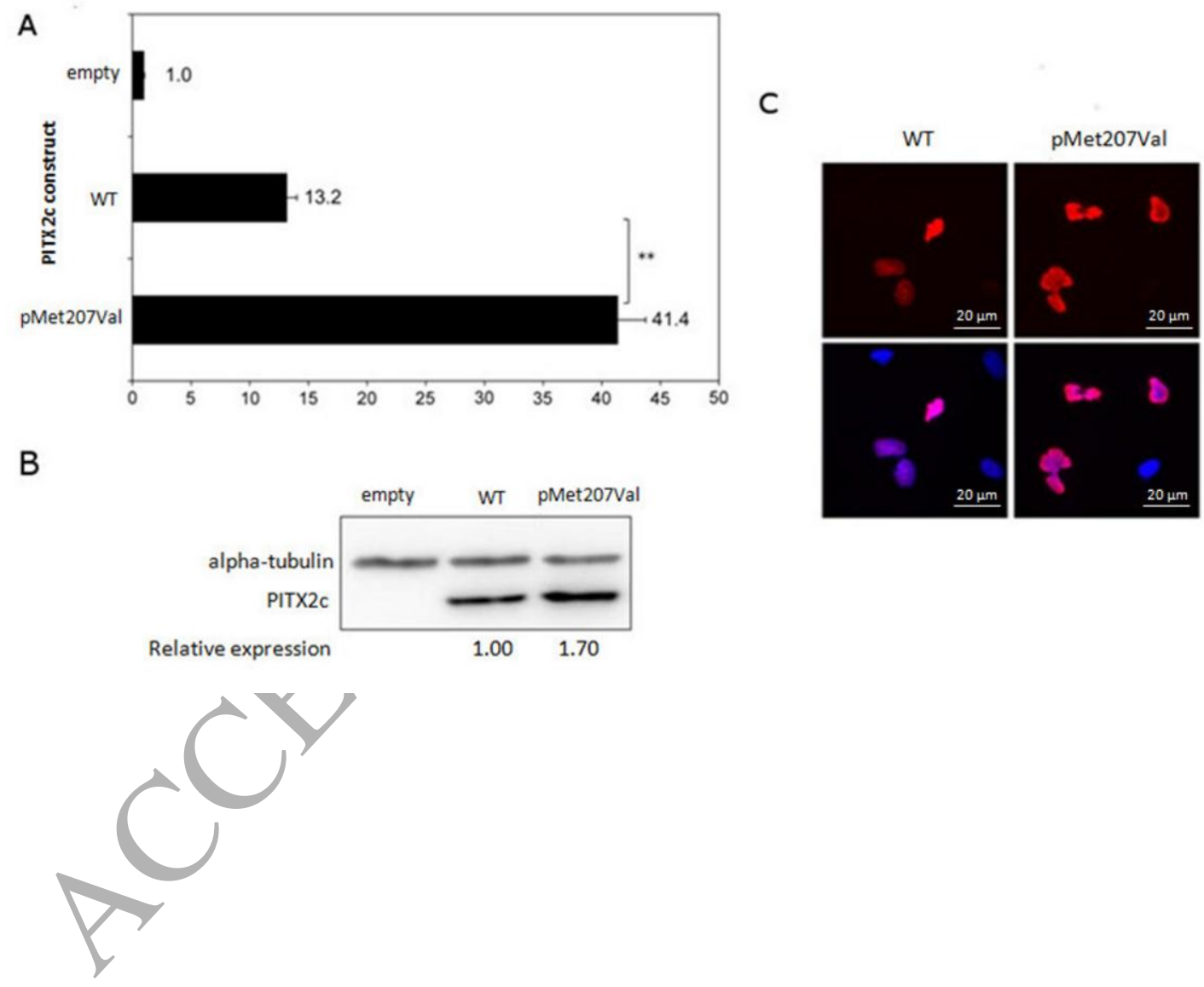
Figure 3. Electrophoretic mobility shift assay in HeLa cells. Electrophoretic mobility shift assay of whole-cell extracts from HeLa cells transfected with pcDNA4: Xpress-PITX2c plasmids (upper panel). Empty expression vector is shown as a negative control displaying a single low-mobility shifted background band due to unknown endogenous protein binding to the Cy3 $3^{\mathrm{TM}_{-}}$-labelled DNA oligomer probe (containing the canonical PITX2 binding element TAATCC). Complexes of probe bound to recombinant PITX2c constructs are shifted to the same location in the respective lanes, with unbound probe migrating to the bottom of the gel. In the lower panel, Western analysis shows the expression levels of the Xpress-PITX2c constructs in HeLa cells, in relation to the alpha-tubulin internal lane control.

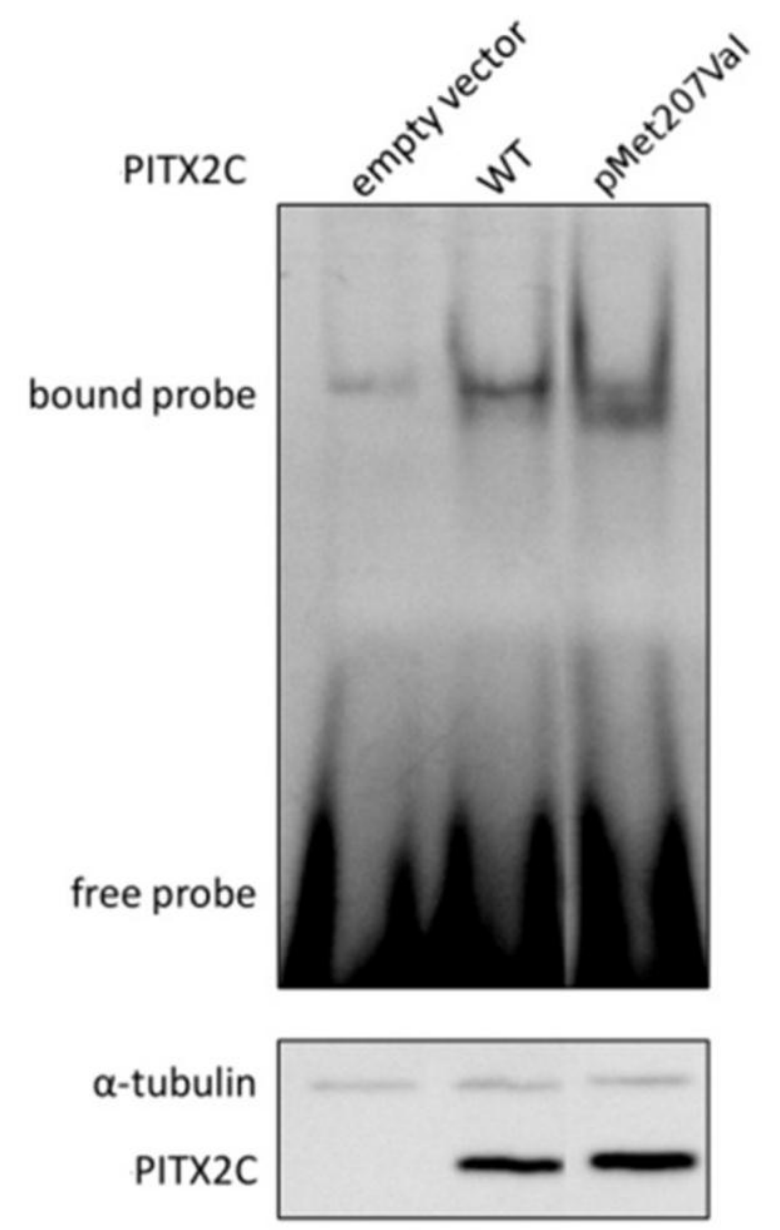


Figure 4. Effects of the PITX2c variant on mRNA transcription in cardiac HL-1 cells. Effect of recombinant PITX2c overexpression on the mRNA levels of $C x 40, C x 43, S C N 1 B$, $K C N Q 1, K C N H 2$ and SCN5A. A. Western blot analysis of V5-tagged PITX2c recombinant proteins expressed in HL-1 cells. WT, WT; NC, non-transfected control; M, p.Met207Val; WT/M, WT/p.Met207Val. GAPDH served as the internal loading control. Each plasmid transfection was done 3 times. B. Semi-quantitative illustration of recombinant PITX2c protein expression normalized to GAPDH corresponding to WT. qRT-PCR analysis of Cx40 (C), Cx43 (D), SCN1B (E), KCNQ1 (F), KCNH2 (G) and SCN5A(H) mRNAs with PITX2c recombinant plasmid transfected in HL-1 cells. Mean +/- SEM are shown. Asterisks illustrate the degree of significance $(* \mathrm{p}<0.05$; and $* * \mathrm{p}<0.01)$ of the differences from WT as evaluated with Student's t-test. Comparisons of WT/M versus M revealed no significant differences $(\mathrm{p}>0.05)$. 
A B

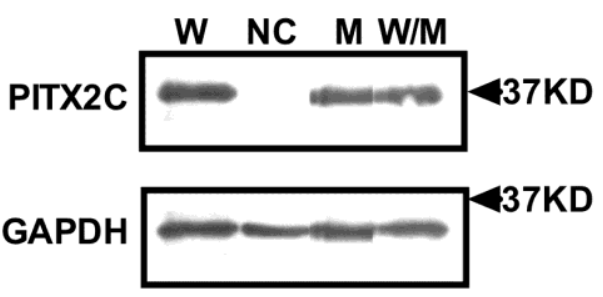

C
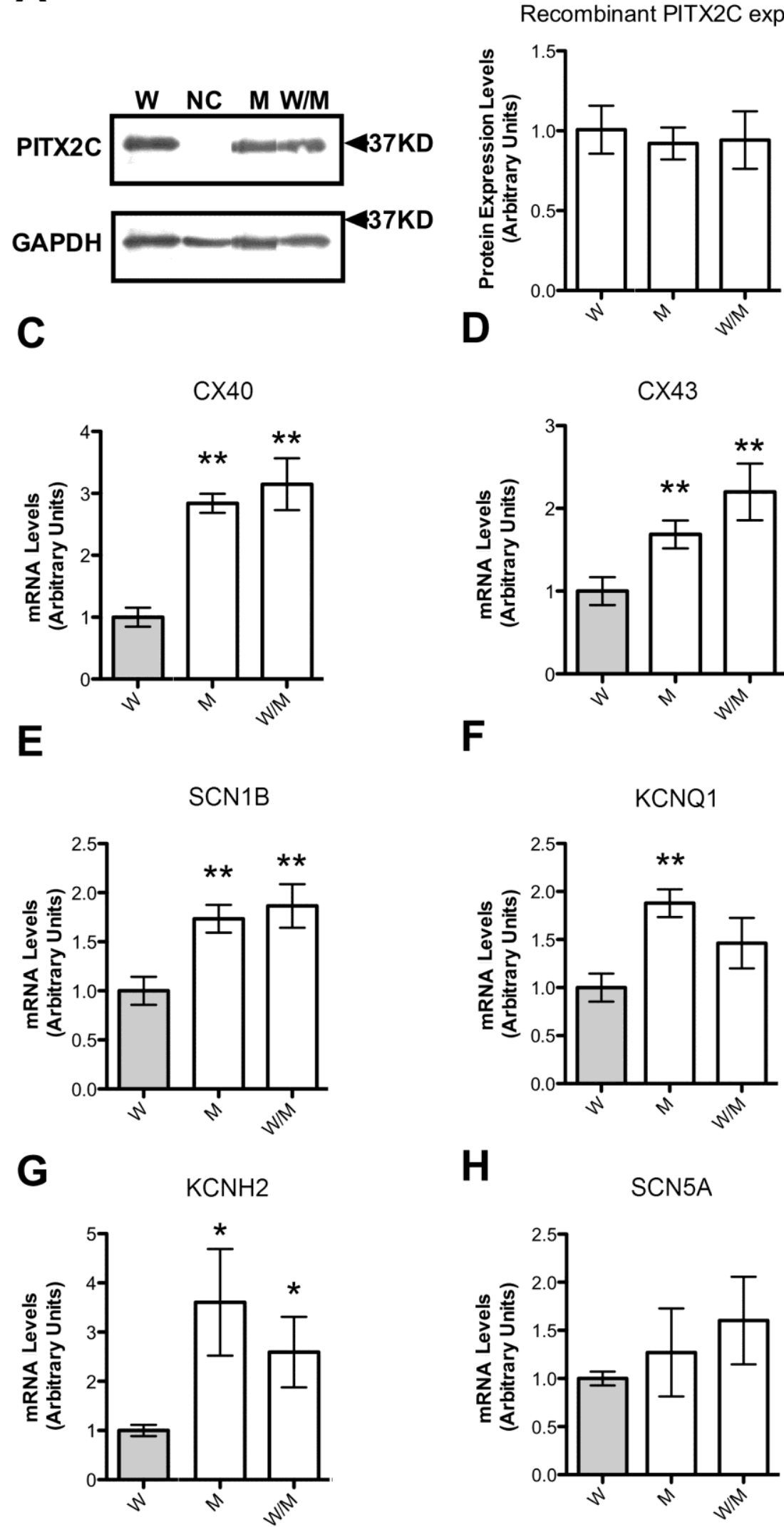

H

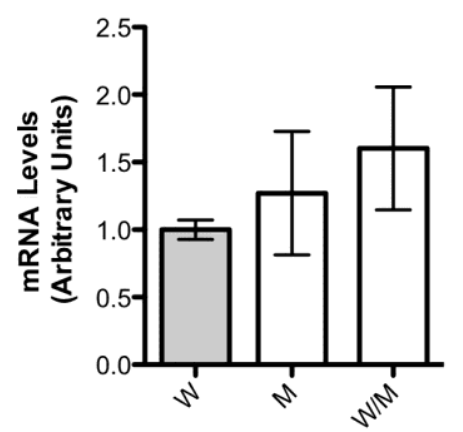


Figure 5: Comparison of non-transfected and mock-transfected HL-1 cells. Levels of connexins and ion channels mRNA in non-transfected (NT) HL-1 cells and in HL-1 cells transfected with the V5-Tag-pcDNA3.1/Zeo vector that did not contain any PITX2 sequence (EV). Note that the empty vector did not cause any change in any of the mRNAs explored, as compared to NT. Each plasmid transfection was done 3 times.
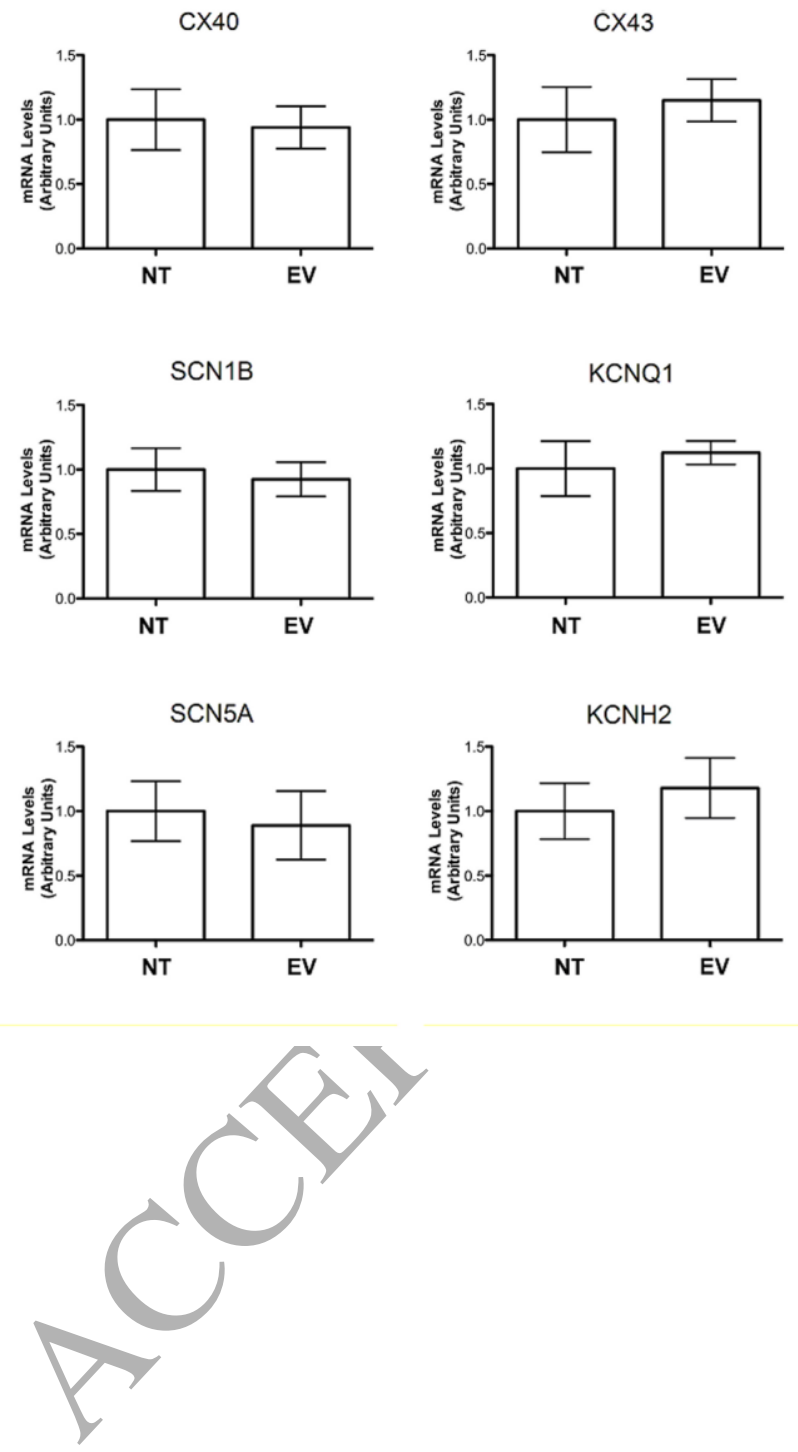
Table 1. Clinical characteristics of the study sample.

\begin{tabular}{lcc}
\hline \multicolumn{1}{c}{ Variable } & Cases & Referents \\
& $\mathrm{n}=60$ & $\mathrm{n}=389$ \\
Male & $41(69 \%)$ & $324(83 \%)$ \\
Age at onset/inclusion*, (years) & $47 \pm 13$ & $57 \pm 12$ \\
Height, (cm) & $175 \pm 9$ & $171 \pm 8$ \\
Weight, (kg) & $86 \pm 22$ & $77 \pm 13$ \\
BMI, (kg/m ${ }^{2}$ ) & $28 \pm 7$ & $26 \pm 4$ \\
Blood Pressure, (mmHg) & & \\
Systolic & $129 \pm 12$ & - \\
Diastolic & $79 \pm 13$ & - \\
AF type & & \\
Paroxysmal & $64.4 \%$ & NA \\
Persistent & $15.2 \%$ & NA \\
Permanent & $18.6 \%$ & NA \\
First degree relative with AF & 34 & - \\
\hline
\end{tabular}

All numbers are reported as mean \pm standard-deviation unless otherwise noted. *For cases we report age at first diagnosis of $\mathrm{AF}$, for referents we report age at inclusion. Parocysmaland persistent combined -, not available; NA, not applicable. 
Table 2. PITX2c variant effects on the mRNA levels corresponding to key proteins involved in AF.

\begin{tabular}{llllll}
\hline GJA5 (Cx40) & GJA1 (Cx43) & SCN1B & KCNQ1 & KCNH2 & SCN5A \\
2.8-fold ** & 1.7-fold ** & 1.7-fold ** & 1.8-fold ** & 3.6-fold * & NS \\
3.1-fold ** & 2.1-fold ** & 1.9-fold ** & NS & 2.6-fold * & NS
\end{tabular}

The levels of mRNA were measured when transfected alone (p.Met207Val PITX2c) or mixed with the WT (p.Met207Val PITX2c+WT PITX2c) and normalized to the mRNA levels observed with WT PITX2c as plotted in Figure 4C-H. NS: No significant changes. ${ }^{*} \mathrm{p}<0.05$; $* * \mathrm{p}<0.01$ 
2

A Novel PITX2c Gain-of-Function Mutation, p.Met207Val, in

6 Asma Mechakra; Tim Footz; Michael Walter; Amelia Aránega; Francisco Hernández-Torres;

7 Elodie Morel; Gilles Millat; Yi-Qing Yang; Mohamed Chahine; Philippe Chevalier; Georges 8 Christé.

9

10 Corresponding author:

11 Georges Christé, Université Lyon 1, EA4612 Neurocardiology, 8 Avenue Rockefeller, 69373

12 Lyon Cedex 08, France.

13 Tel: +33627556373

14 Fax: +33478777185

15 Email: christe.georges@laposte.net 16 
Supplemental methods

$\begin{array}{ll}\text { Supplemental tables } & 7\end{array}$

Table S1. The intronic primers used for amplification of the exons and splice sites of PITX2c

Table S2. Primers used in the preparation of constructs for experiments in HL-1 cells 8

Table S3. Oligonucleotide sequences used for qRT-PCR analysis in HL-1 cells. 9

Table S4. Alignment of multiple PITX2c protein sequences across species 10

$\begin{array}{ll}\text { Limitations of the study } & 11\end{array}$

17 


\section{Supplemental methods}

\section{Study sample}

A cohort of 60 unrelated patients with idiopathic AF was recruited in this study. The patients had a mean age of 58 years (22-91 years) and 70\% were male. All the patients were of western European descent. Among the patients, 47 had paroxysmal AF, 8 had permanent AF and 5 had persistent AF. The available relatives of the mutation carriers and a total of 389 ethnically-matched, unrelated healthy individuals used as controls were included. Clinical data including medical records, electrocardiogram (ECG) and echocardiography reports were collected. The study participants were clinically classified using a consistently applied set of definitions. Briefly, diagnosis of AF was made by an electrocardiogram demonstrating no P waves and irregular R-R intervals. All individuals gave written informed consent. The study conforms to the principles of the Declaration of Helsinki and the local institutional or regional ethics committees approved all experimental protocols. Other recognized cardiovascular diseases, hypertension and metabolic or pulmonary diseases had been excluded in all cases.

\section{Genetic Analysis of PITX2}

Genomic DNA from all participants was extracted from whole blood samples with the FlexiGene DNA Kit (Qiagen, Hilden, Germany). The entire coding sequence of PITX2c was directly sequenced in 60 unrelated patients with early onset AF, available relatives of the variant carriers and in 389 ethnically matched healthy referent individuals. The referential The genomic DNA sequence of PITX2c was derived from GenBank [GenBank Acc. No.: NC_000004]. With the aid of online Primer 3 software (http://frodo.wi.mit.edu), the primer pairs used to amplify the coding exons and intron-exon boundaries of PITX2c by polymerase chain reaction (PCR) were designed as shown in Supplemental Table S1. The coding exons were amplified using HotStarTaq polymerase (Qiagen) with standard conditions and concentrations of reagents. Amplified products were purified from agarose gel using 
Biospin Gel Extraction Kit (BioFlux, Hangzhou, China). Both strands of each PCR product were sequenced with the BigDye ${ }^{\circledR}$ Terminator v3.1 Cycle Sequencing Kit (Applied Biosystems, Foster, CA, USA) on an ABI PRISM 3130 XL DNA Analyzer (Applied Biosystems). DNA sequences were analyzed with the DNA Sequencing Analysis Software v5.1 (Applied Biosystems). Sequence variants were validated by resequencing an independent PCR-generated amplicon from the subject and met our quality control threshold with a call rate exceeding $99 \%$. Sequencing of genes previously associated with AF was performed: KCNQ1, KCNH2, , KCNA5, SCN5A, GJA1, GJA5 and GJC1.

\section{Reporter gene assay in HeLa cells}

A reporter assay was performed to assess the ability of PITX2c proteins carrying the p.Met207Val variant to transactivate a luciferase reporter plasmid driven by a fragment of the promoter from the target gene SLC13A3. The pGL3Basic-SLC13A3 reporter ("-163/+165") plasmid was designed to include the predicted PITX2 binding site A, as described by Strungaru et al.\{Strungaru, 201129952 /id\} The PITX2c-expressing plasmid or the empty expression vector (500 ng) was co-transfected with $60 \mathrm{ng}$ of pGL3Basic-SLC13A3 reporter \{Strungaru, 201129952 /id\} and $30 \mathrm{ng}$ of $\mathrm{pCMV} \beta$ transfection control vector (Clontech Laboratories, Inc., Mountain View, CA, USA) into HeLa cells ( 4x104 per 15 mm well, 24-well plate) with $0.5 \mu$ of transfection reagent. Cells were harvested with $100 \mu 1$ of $1 \mathrm{x}$ Reporter Lysis Buffer (Promega, Madison, WI, USA) 48 hours post-transfection. Firefly luciferase activity caused by activation of the SLC13A3-reporter plasmids was measured by luminometry (Turner Designs, Sunnyvale, CA, USA) from $10 \mu$ of protein lysate mixed with $100 \mu \mathrm{l}$ of Luciferase Assay Reagent (Promega) and standardized to the $\beta$-galactosidase activity (internal control) as quantified by the $\beta$-galactosidase Enzyme Assay System (Promega) from $50 \mu \mathrm{l}$ of protein lysate. Luciferase values from activation of the SLC13A3reporter plasmids were normalized to $\beta$-galactosidase (expressed from the transfection control 
plasmid) and expressed relative to the ratio for empty expression vector plus non-deleted SLC13A3 reporter ("-163/+165"). Nine replicates of each sample were tested.

\section{Electrophoretic Mobility Shift Assay}

To assess electrophoretic Mobility Shift Assay, Cy3 ${ }^{\text {TM}}-$ labeled DNA oligomers containing the bicoid binding site were manufactured by Integrated DNA Technologies, Inc. (San Diego, CA, USA) and assembled by renaturing (forward, 5'-GAT CCA AAT AAT CCC AAC AGA-3'; reverse, 5'-GAT CTC TGT TGG GAT TAT TTG-3'). Whole cell lysates were prepared from HeLa cells transfected with pcDNA4:Xpress-PITX2c plasmids. Doublestranded fluorescent DNA probes at $0.5 \mu \mathrm{M}$ were incubated with $40 \mu \mathrm{g}$ of whole cell extracts for 20 minutes in $20 \mu \mathrm{l}$ reaction volumes containing $5 \%$ glycerol, $1 \mathrm{mM}$ dithiothreitol, $1 \mu \mathrm{g}$ poly(dI-dC), $5 \mu \mathrm{g}$ single-stranded salmon sperm DNA. Samples were electrophoresed in nondenaturing $6 \%$ polyacrylamide gels in $1 \mathrm{X}$ Tris-Glycine-EDTA buffer at $15 \mathrm{~V} / \mathrm{cm}$ at room temperature. The gel was subsequently scanned using the Kodak Image Station 4000MM (excitation wavelength of $535 \mathrm{~nm}$; exposure filter for $600 \mathrm{~nm}$ ) and Kodak Molecular Imaging Software v4.0.5.

\section{Western blot analyses of proteins of HL-1 cells}

Western blot analysis was subsequently performed to compare PITX2c expression in HL-1 cells under different conditions. Cells were harvested in Laemmli's SDS sample buffer $24 \mathrm{~h}$ after transfection. Samples were resolved on $12 \%$ SDS (w/v) polyacrylamide gels and the proteins were transferred onto nitrocellulose membranes (Protran Whatman, Maidstone, UK). After blocking the membrane 30 minutes in PBST (PBS-0.05\% (v/v) Tween) containing 5\% $(\mathrm{w} / \mathrm{v})$ skimmed milk powder (blocking solution), the blot was incubated for $90 \mathrm{~min}$ in either a 1/10000 dilution of mouse monoclonal anti-V5 (V8012, Sigma-Aldrich) or a 1/15000 dilution of mouse monoclonal anti-GAPDH (G8795, Sigma-Aldrich) antibodies in blocking solution. Subsequently it was washed three times for $10 \mathrm{~min}$ with PBST and then incubated for $30 \mathrm{~min}$ 
in a 1:5000 dilution of peroxidase-conjugated anti-mouse IgG antibody (Sigma-Aldrich) in PBST. The membrane was washed twice for 10 min with PBST followed by a final wash in PBS for 10 min. Bound antibodies were detected by ECL Plus Western blotting (Amersham, Uppsala, Sweden). Protein expression was quantified using the online software GelAnalyzer (http://www.gelanalyzer.com/).

\section{Quantitative Reverse Transcriptase-PCR Analyses in HL-1 cells}

Transfected HL-1 cells were collected 24 hours after transfection and processed for RNA isolation using the SV Total RNA isolation system (Promega). RNA quality and integrity was evaluated using a Nanodrop spectrophotometer. For cDNA synthesis, $0.5 \mu \mathrm{g}$ of total RNA was used in a $20 \mu \mathrm{l}$ reaction volume with the Maxima first strand cDNA synthesis kit (Fermentas life science, Ontario, Canada). Quantitative RT-PCR measurement was performed with SsoFastTM EvaGreen (BioRad) and CFX384 QPCR System (BioRad) following the manufacturer's instructions, and using the primers shown in Supplemental

\section{Table S3.}

\section{Web Resources}

The following web resources have been used: Exome Variant Server (EVS), NHLBI GO Exome Sequencing Project (ESP), Seattle, WA (URL:

http://evs.gs.washington.edu/EVS/) [October 2018 accessed].

Exome Aggregation Consortium (ExAC), Cambridge, MA (URL:

http://exac.broadinstitute.org) [October 2018 accessed]. Online Mendelian Inheritance in Man (OMIM), (URL: http://www.omim.org/)

[October 2018 accessed]. Single Nucleotide Polymorphism database, the National Center for Biotechnical Information (http://www.ncbi.nlm.nih.gov/SNP/)

Accession Numbers: The OMIM accession number for the PITX2 sequence reported in this paper is MIM 180500. 


\section{Supplemental tables}

118

119 Table S1. The intronic primers used for amplification of the coding exons and splice sites of PITX2c.

\begin{tabular}{llll}
\hline Exons & Forward primer & Reverse primer & Amplicon size (bp) \\
\hline 6 & cag,ctt,ggc,ttg,aga,act,cg & tga,ctt,cct,tgg,ggc,gag,ag & 442 \\
7 & cag,ctc,ttc,cac,ggc, ttc,tg & gct,gcc,ttc,cac,att,ctc,tc & 387 \\
8 & aat,ctg,cac,tgt,ggc,atc,tg & agt,ctt,tca,agg,gcg,gag,tt & 677 \\
\hline
\end{tabular}

120 
121 Table S2. Primers used in the preparation of constructs for experiments in HL-1 cells.

V5 tag primers

MCV5_F01 GGGGCGGCCGCATGGGAAAGCCGATCCCAAACCCTCTATTA

GGTCTGGACTCCACCGGATCCTGAGATATCGGG

MCV5_R01 CCCGATATCTCAGGATCCGGTGGAGTCCAGACCTAATAGAG

GGTTTGGGATCGGCTTTCCCATGCGGCCGCCCC

Pitx2c constructions primers

OrfH_Pitx2cf02 CCCTCTAGAATGAACTGCATGAAAGG

OrfH_Pitx2cr02 CCCGCGGCCGCACACGGGCCGGTCC

122

123 
124 Table S3. Oligonucleotide sequences used for qRT-PCR analysis in HL-1 cells.

\begin{tabular}{ll}
\hline & Mouse qRT-PCR primers \\
\hline Gusb_F & ACGCATCAGAAGCCGATTAT \\
Gusb_R & ACTCTCAGCGGTGACTGGTT \\
Scn1b_F & TGCTCATTGTGGTGTTGACC \\
Scn1b_R & CCTGGACGCCTGTACAGTTT \\
Kcnq1_F & TTCGCCACATCAGCTATCAG \\
Kcnq1_R & ATCTGCGTAGCTGCCAAACT \\
Scn5a_F & CTTCACCAACAGCTGGAACA \\
Scn5a_R & CATGACGAGGAAGAGGAGGA \\
Kcnh2_F & GCACTCCAGAGACAGCTGAA \\
Kcnh2_R & AACCTGAGAAAGCGAGTCCA \\
Connexin 40_F & CAGAGCCTGAAGAAGCCAAC \\
Connexin 40_R & ATGCGGAAAATGAACAGGAC \\
\hline
\end{tabular}

125 
126 Table S4. Alignment of multiple PITX2c protein sequences across species. The methionine residue at

127 position 207 is highly conserved

\begin{tabular}{lcl}
\hline Species & aa number & Alignment \\
\hline Homo sapiens & $139-238$ & WAAKGLTSASLSTKSFPFFNSMNVNPLSSQSMFSPPNSISSM \\
Pan troglodytes & $139-238$ & WAAKGLTSASLSTKSFPFFNSMNVNPLSSQSMFSPPNSISSM \\
Macaca mulatta & $139-238$ & WAAKGLTSASLSTKSFPFFNSMNVNPLSSQSMFSPPNSISSM \\
Rattus norvegicus & $139-238$ & WAAKGLTSASLSTKSFPFFNSMNVNPLSSQSMFSPPNSISSM \\
Mus musculus & $139-238$ & WAAKGLTSASLSTKSFPFFNSMNVNPLSSQSMFSPPNSISSM \\
Canis familiaris & $139-238$ & WAAKGLTSASLSTKSFPFFNSMNVNPLSSQSMFSPPNSISSM \\
Felis catus & $139-238$ & WAAKGLTSASLSTKSFPFFNSMNVNPLSSQSMFSPPNSISSM \\
Bos taurus & $139-238$ & WAAKGLTSASLSTKSFPFFNSMNVNPLSSQSMFSPPNSISSM \\
Gallus gallus & $126-225$ & WAAKGLTSASLSTKSFPFFNSMNVNPLSSQSMFSPPNSISSM \\
Tetraodon & $69-166$ & WAAKGLTPASLSTKSFPFFNSMNVNPLSSQTMFSPPNSISSM \\
nigroviridis & $137-236$ & WAAKGLTSASLSTKSFPFFNSMNVNPLSSQSMFSSPNSISSM \\
\hline
\end{tabular}

